\title{
HOW TO EVALUATE A TRANSITION - ORIENTED FUNDING PROGRAMME? LESSONS LEARNED FROM THE EVALUATION OF FONA, THE GERMAN FRAMEWORK PROGRAMME TO PROMOTE SUSTAINABILITY RESEARCH
}

\author{
SARAH SEUS AND SUSANNE BUEHRER \\ DOI: $10.22163 /$ fteval.2021.515
}

\section{ABSTRACT}

$\mathrm{T}$ This article is based on the evaluation of the German research funding programme "FONA - Forschung für Nachhaltigkeit" (Research for Sustainability.) It reflects upon the methodological challenges confronting the evaluation. These challenges result from the specific objectives and design of the FONA programme (a strategic portfolio of heterogenious interventions). FONA's ambition is to fund activities under the emerging field of 'sustainability research'. The core characteristics of sustainability research are: interdisciplinary and transdisciplinary research processes; orientation towards transferring the research results (into society) and the interdependency with a wider system and global perspective.

For illustration purposes, a selection of key evaluation results is presented. These results highlight the effects that the funding has had on the research community, the development of sustainability research in Germany, and the effects on non-scientific sectors (especially the economy and the public sector). The article concludes that the evaluation's design (multi-level and multi-method approach, theory-based evaluation) was suitable for tracing the different effects in different impact domains. It is especially suitable for analysing interventions that aim at institutional changes in academia and societal transformation.

\section{INTRODUCTION}

Sustainability research is not a clearly defined scientific discipline, nor can it be pinned down to specific topics ${ }^{1}$. There are two connecting elements of sustainability research (Komiyama and Takeuchi 2006; Gallopín et al. 2001): first, the alignment of scientific research to societal problems in order to contribute to societal transformation processes. Second, how the research is conducted. Sustainability research aims at providing solutions to existing societal (grand) challenges such as climate change or biodiversity conservation. Hence, the usability and transferability of research results into non-academic settings form a core component of sustainability research. This implies changes to the research process itself: Sustainability research aims at transcending disciplinary boundaries by combining different scientific disciplines to address a problem (for a definition of "interdisciplinarity", see van den Besselaar and Heimeriks (2001)). It involves non-scientific stakeholders both in the definition of the research questions and in the execution of the research work (definition of "transdisciplinarity" according to Pohl (2011)). It also includes an international perspective, especially the implications of the research for countries in the Global South (internationality). In sum, the FONA funding approach reflects a systemic perspective of research and considers the different impacts that research can have beyond the scientific community.

Applying these characteristics to research, sustainability research has been a fast growing field over the last 20 years $^{2}$ (Bührer et al. 2020b) and has gained importance and recognition both within and outside the scientific community.

\section{FONA - GERMAN FEDERAL RESEARCH FUNDING FOR SUSTAINABILITY}

In recent years, research funding organisations and research funding have increasingly referred to global challenges and sustainability goals in their strategies and research calls. Since 2015, most references have been made to the sustainable development goals (SDG). The German framework programme for sustainability research FONA “Forschung für

Indeed, there is not even a commonly agreed name for it. The expression "sustainability science " is used when speaking about the scientific discipline (see Koniyama et al. 2006), but the expression "sustainability research" is found when (transformative) research processes are investigated (see Wiek et al. 2016). The BMBF named its funding programme "Research for Sustainability". For simplification reasons, we use the term "sustainability research".

2 The formation of a new research discipline can be measured in a) a high increase in the number of publications in the last years, b) the creation of new academic journals focusing on the topic, c) institutional changes in research-performing organisations, e.g. the creation of research groups and research institutes dedicated to the new research discipline.

3 The four phases of FONA are: FONA 1: Research for Sustainability (2005-2009), FONA 2: Research for Sustainable Development (2010-2014) and F0NA 3 : Research for Sustainable Development (2015-2019), FONA 4: FONA Strategy (2020-2025). 
Nachhaltigkeit" is one of the early examples of this trend. The German Federal Ministry of Education and Research (BMBF) established FONA in 2005. Since then, three programming phases have been implemented. The fourth FONA phase was launched in $2020{ }^{3}$

FONA has been designed to emphasize the interactions along value chains and between environmental, economic and societal processes. With the FONA framework, the BMBF focused at a very early stage on a type of research that did not only target pure knowledge generation or the generation of innovations as such, but was explicitly oriented towards global challenges and included the perspectives of diverse societal stakeholders. Furthermore, the FONA framework considers wider policy discussions in Germany and on EU / global level with regard to sustainable development.

These rationales led to the development of FONA's core elements that are still at the heart of FONA research projects today: interdisciplinarity, transdisciplinarity, solution and transfer orientation, internationality and systems thinking. The main concern in early FONA periods was setting the stage, especially integrating the core elements of sustainability research into the research funding procedures and research processes. The following objectives guided the first two FONA periods:

- Promote sustainability research (i.e. improve the knowledge base) and strengthen sustainability research specifically in Germany.

- The funded projects should produce results that are applicable and useful in practice and help to address societal challenges. In addition to technologies and marketable products, this explicitly included knowledge and recommendations that can be used for political decision-making processes or public planning.

The overall ambition of FONA is to change the way individuals and organisations think and act with regard to sustainable development, both in academia and wider society.

Between 2005 and 2019, a total funding volume of approximately 5 billion euros was disbursed. About 10,000 research projects received funding. The activities supported by FONA were highly diverse: traditional research collaboration projects, but also junior research groups and research infrastructures such as submarine robots and the research vessel "SONNE"4. It also provided funds for secretariats and research coordination bodies, such as the secretariat of ICPP Working Group III (2008-2015). Funding was not only channelled to applied research, but also towards basic research.

The beneficiaries of FONA are also heterogeneous: $78 \%$ of funding is assigned to research performing institutions, both universities and nonuniversity research institutes. $14 \%$ of the funding goes to companies, both SMEs and large enterprises. Approximately $7 \%$ of the beneficiaries are other societal stakeholders, either local / regional authorities or civil society organizations. In terms of the topics funded, FONA covers a wide range of environmental topics ranging from polar research to sustainable materials, and biodiversity protection to social-ecological research.

The following contribution is based on an evaluation of the FONA strategic framework, especially FONA 1 and FONA 2. Its aim is twofold: First, it discusses the methodological challenges of the evaluation resulting from FONA's objectives that go beyond traditional research funding rationales and from the framework's complex design. Second, selected evaluation findings are presented to show how FONA has contributed to change processes at the level of stakeholders and organisations and at the (research) system's level to some extent.

\section{EVALUATION DESIGN AND METHODOLOGICAL CHALLENGES}

The evaluation of FONA 1 and 2 periods was designed as an ex-post evaluation aimed at providing information about the following categories: goal achievement, effectiveness, efficiency and programme management. Its purpose was mainly accountability, but it also included elements of learning, especially with regard to the future development of the FONA framework.

The evaluation faced the following specific challenges:

1. The FONA framework is versatile, complex and - in the German funding landscape - unique: it incorporates a broad variety of research funding instruments, beneficiaries, topics and research modes. The high number of individual programmes and the variety of actors administrating the activities under the umbrella of the FONA Strategy pose challenges for data collection as well as for the aggregation of data and an analysis at framework level.

2. The (emergent) characteristics of sustainability research (interand transdisciplinarity, a systemic and international perspective when conducting research) are common elements of most research activities. However, these core elements of sustainability research are a new way of perceiving and doing scientific research This new approach raises questions about the criteria used to evaluate the quality of these new research collaborations and their results.

3. FONA-funded research intends to have effects not only on the science system, but on other societal spheres as well. Currently, there is a broad discussion within STI communities of how to measure the effects of research projects beyond the science sector and relate the funding stimulus to wider impacts. However, so far there is no agreed methodology to qualify societal impacts (Bührer et al. 2021, pre-published) and further methodological and conceptual efforts are needed to capture such effects.

The evaluation addressed these challenges as follows: Challenge number 1 was addressed by a multi-level analysis of the programme implementation and by combining qualitative and quantitative, reactive and non-reactive methods as shown below. 
Figure 1: Methodological approach of the FONA evaluation
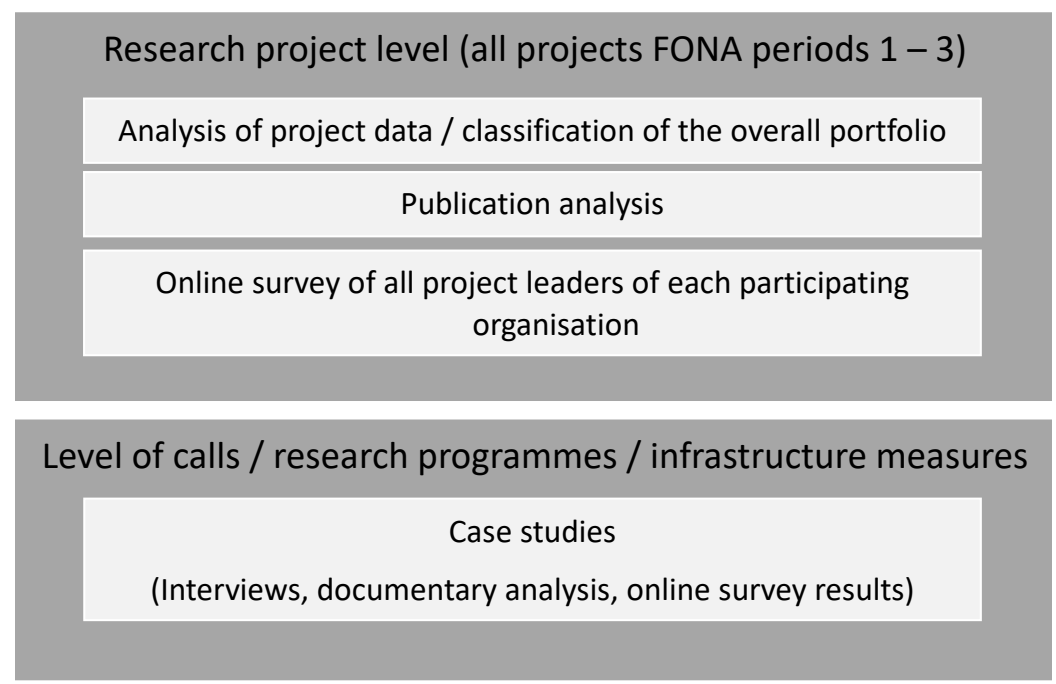

Framework level / Strategic programming

Expert interviews: Ministry staff involved in FONA administration / National and international stakeholders

Focus group discussions with beneficiaries (researchers, companies, public administrations)

Source: Fraunhofer ISI, own illustration

More specifically, the following methods were used: an online survey resulting in 3,843 valid records, 80 interviews, three focus groups with 26 participants in total, and 20 case studies involving desk research as well as interviews. In addition, bibliometric analyses, document analyses and the analysis of the German federal research funding database "profi" were used.

Challenge number 2 was addressed by including the core elements of sustainability research as stand-alone evaluation criteria. These criteria (interdisciplinarity, transdisciplinarity, transfer orientation, systemic perspective, internationality) can be seen as necessary features of research processes without which impacts on society and changes at the level of the science system cannot unfold.

Challenge number 3 was addressed by systematically covering both impact levels (see Figure 2) and various impact dimensions. Specifically, the evaluation approach reflected that FONA's objective is to reach the different levels at which funding is intended to have effects (the microlevel of individual beneficiaries / researchers, the meso-level of involved organisations like universities, enterprises, municipal actors, and finally the macro-level of the national economy and society). Furthermore, not only typical scientific and economic impacts were considered, but also environmental impacts, societal impacts as well as policy and systemic impacts.

The following figure shows the different levels at which effects are intended, as well as the different impact dimensions addressed by the funded research. This logic model was developed at the beginning of the evaluation and further refined during the evaluation. It has helped to operationalise the intended effects in each "sector" and was used as the basis for developing indicators and / or descriptors. For the micro-level, we used primarily traditional scientometric indicators (e.g. publication and citation rate, co-publication rate) as well as other well-known research performance indicators of , including effects on research actors (e.g. career development). The novelty of our evaluation was to define descriptors for the meso level. For each type of organisation considered at the meso level (science, business, public administration), an intervention logic was outlined, focusing on the expected results on the research landscape, the economy, public policy and administration. These intervention logics used either existing indicators, derived from numerous evaluation studies focusing on science-industry-relations, or developed descriptors qualifying the results for the four selected areas.

The impact model of FONA funding was also designed to observe and record potential effects on the overall economy as well as on society and political processes at the macro level. However, the aim was not a final quantification of the program and its effects. This is not possible due to the following specifics of the programme: Research for sustainability is about generating new (action) knowledge. However, the studied phenomena are embedded in a system in which different rationalities, stakeholders and activities are interwoven and interdependent. An individual impulse can have an effect, but it has to be considered in its ecosystem and network of influencing factors.

The complexity of the programme would have required different approaches to data generation in order to quantify its effects on a macro level. It would also have required a determination of the status quo beforehand and a definition of the relevant target values. As these were not part of FONA's strategic framework, it was not possible to quantify its contributions. For this reason, we used case studies to trace plausible cause-effect relationships based on theory-based impact models. Ultimately, these case studies often remain at the level of anecdotal evidence. 
Figure 2: Overview of expected impacts of FONA

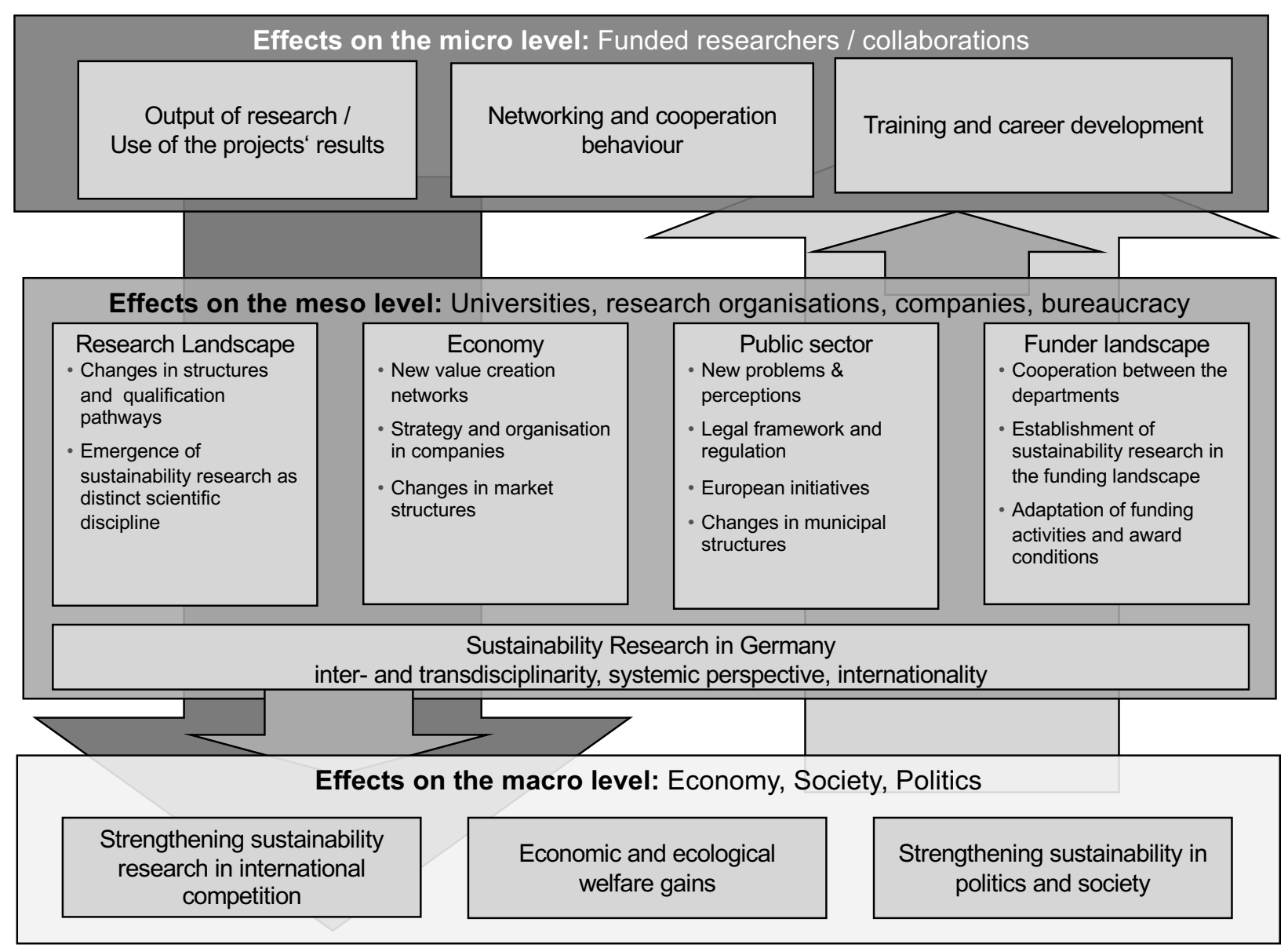

\section{SELECTED RESULTS TO ILLUSTRATE THE MULTIPLE EFFECTS OF FONA FUNDING}

In this chapter, we present selected findings of the evaluation and focus especially on how the FONA funding has contributed to trigger change processes among researchers, and research organisations, to develop and strengthen a German community for sustainability research, and has also reached out into society.

\section{SETTING THE BAR FOR INTERDISCIPLINARY RE- SEARCH COOPERATION}

Interdisciplinary collaboration was very high in FONA projects. In 75\% of the projects surveyed, more than two disciplines worked together. In about a quarter of the projects, engineering and natural scientists worked together with researchers from the humanities, social and cultural scientists.
Figure 3: Percentage of interdisciplinary research projects

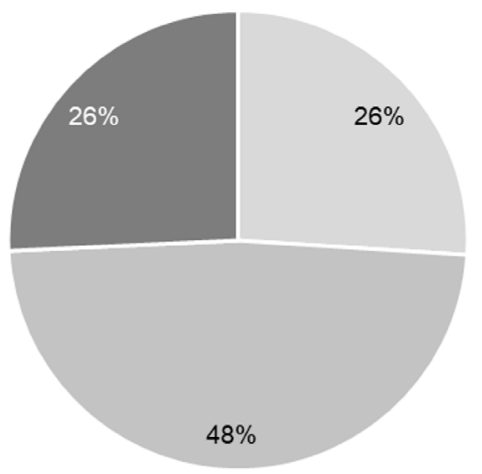

$n=2593$

mono-disciplinary projects

weak interdisciplinary projects (collaboration within natural/ engineering science of within SSH)

strong interdisciplinary projects (collaboration between STEM \& Social Science and Humanities disciplines 
The cooperation in interdisciplinary consortia was rated very positively by the project leaders interviewed. There were some obstacles such as communication and internal team organisation problems, but these were not dominant. Findings from the expert interviews, case studies and the focus group on interdisciplinarity indicated that the interdisciplinarity functioned, but that clear potential for improvement remains, especially with regard to the joint formulation of research questions. This may also be due to the fact that interdisciplinarity is now required in many FONA calls for proposals, but the criteria for assessing the intensity of interdisciplinary exchange in the proposed research projects are not sufficiently clear. The evaluation concluded that the BMBF, as the largest German funding body for sustainability research, has contributed to further advancing interdisciplinary research and to qualifying a community of scientists for this type of research through the FONA programmes.

\section{STRENGTHENING SUSTAINABLE RESEARCH}

The overall aim of the Federal Ministry's funding scheme is to finance excellent research and to increase the visibility and reputation of German research internationally. The analysis of the publications of the project leaders involved in FONA showed that the FONA-funded researchers published a lot and well across all the indicators traditionally considered relevant to measure research excellence, such as the number of co-publications and citation rates. In addition, all the indicators showed an increase between funding period 1 and funding period 2, as shown in the next figure.

\section{CHANGE PROCESSES IN COMPANIES}

During the FONA funding periods, the benefitting companies reported an increased awareness of sustainability issues, new activities (e.g. resource-saving activities) and even organisational changes to company structure (e.g. changes in business units or in the strategic orientation of the company) (see Figure 5 for details). To a certain extent, these developments can be explained by the participation in collaborative research projects and interaction with partners. However, external triggers, such
Figure 4: Citation rate of FONA beneficiaries in comparison to other countries in the field "sustainability"

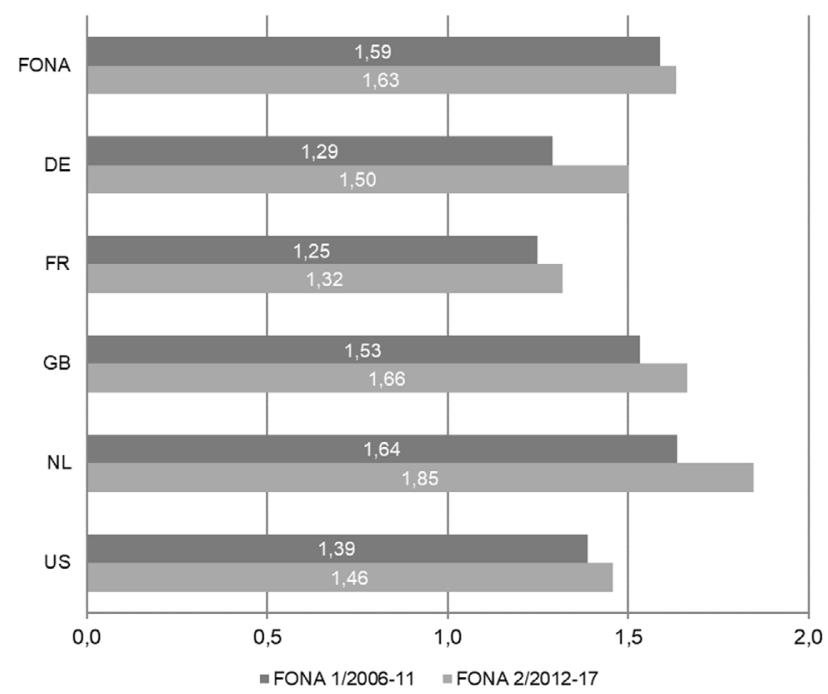

Source: Scopus data, calculation Fraunhofer ISI

Furthermore, the analysis of co-publications shows that the German research community in the different disciplines related to sustainability research has become well connected over time, particularly within Germany, but increasingly also internationally.

Figure 5: Structural effects on corporate strategies

Increased sensibility and awarness of SD issues within the
company

Strategic orientation of the company towards sustainability

Anchoring SD in the corporate culture
$\begin{gathered}\text { Organisational changes to reflect SD (e.g. creation of new } \\ \text { organisational units) }\end{gathered}$
Changes in organisational practices
Implementation of resource-saving efficient corporate
activities

as changes in the demand for more sustainable products or processes, increased consumer awareness and more legal requirements, (e.g. the CRS reporting obligation), also have a strong influence on company behaviour with regard to sustainable development. Sustainability is now a priority in many companies. FONA was able to benefit from these external influencing factors.

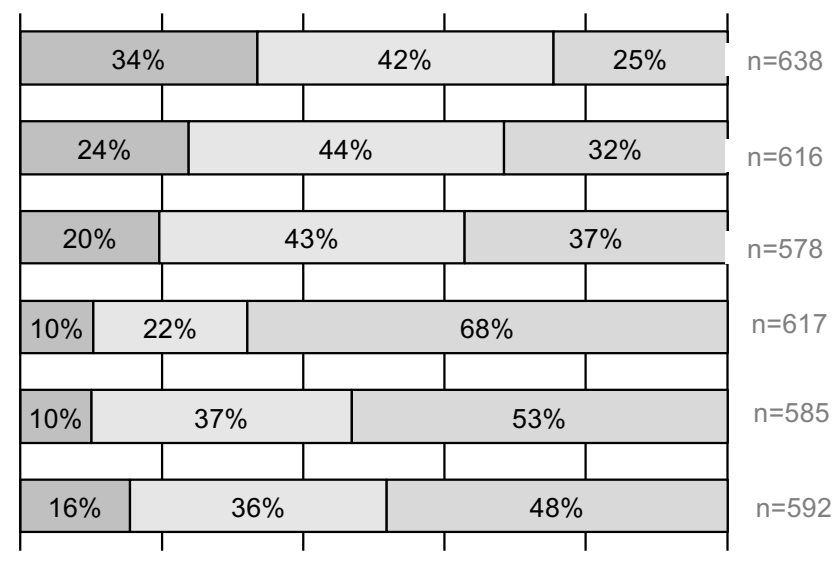

口yes apartialy $\square$ no 


\section{REACHING OUT TO NON-SCIENTIFIC STAKEHOLDERS}

FONA's aim to reach out to societal stakeholders can be seen in Figure 6, which shows the target groups of research projects.

Figure 6: Target groups of research results

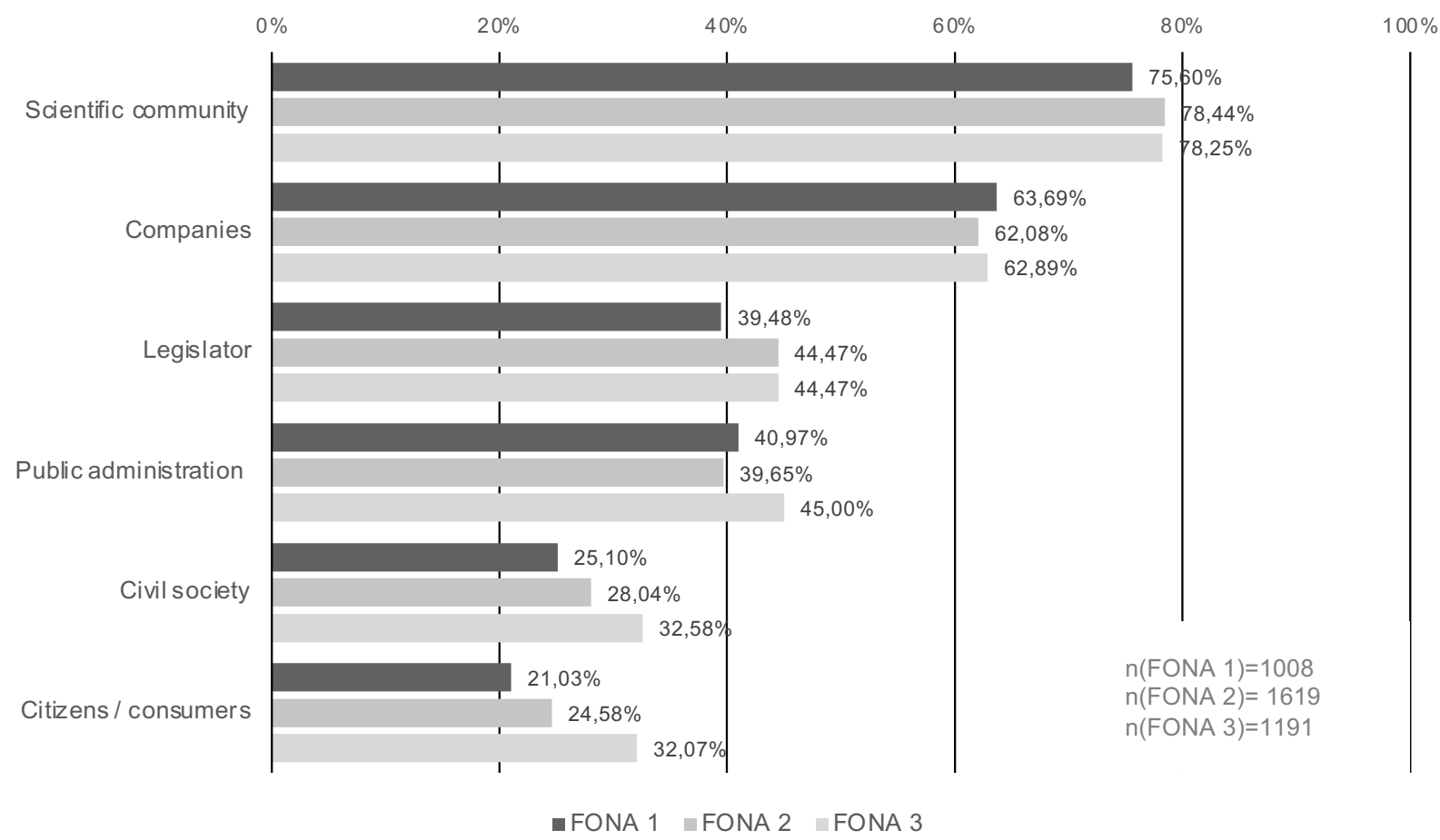

Source: Survey of project leaders 2018, calculation Fraunhofer ISI

As expected for a research programme with a long tradition in environmental technologies, the largest target groups are scientists and RGI performing companies. However, the evaluation showed that public and societal stakeholders are also seen as direct users of research results. The importance of these groups grew continuously and statistically significantly between FONA 1 and FONA 3. It is expected that this trend will continue in the current FONA Strategy.

The evaluation found that about $40 \%$ of the funded FONA projects were transdisciplinary cooperation projects in the narrower sense ${ }^{5}$, i.e. cooperation that includes societal stakeholders and public administration in research projects. Over the course of the FONA periods, there was an increase in such transdisciplinary alliances.
Figure 7: Type of stakeholders involved in transdisciplinary research projects

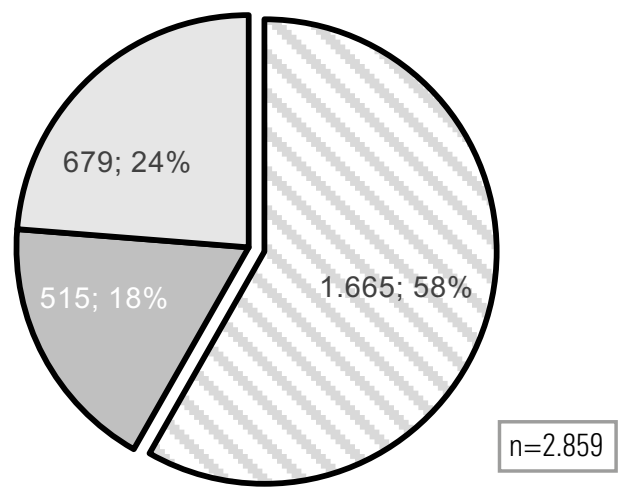

Science - companies collaborations

Science - Public or civil society organisation collaborations

Science - companies - public/ civil organisations collaborations

$5 \quad$ As Ryl activities can also be performed in companies, the decision was to made to exclude collaboration between science and industry actors from the evaluation, i.e.transdisciplinarity in a broader sense. 
Working in inter- and transdisciplinary projects made research more relevant to societal problems, but was also more innovative, at least from the viewpoints of the survey respondents (see figure below).

Figure 8: Assessment of innovativeness and relevance of research results in collaborative projects

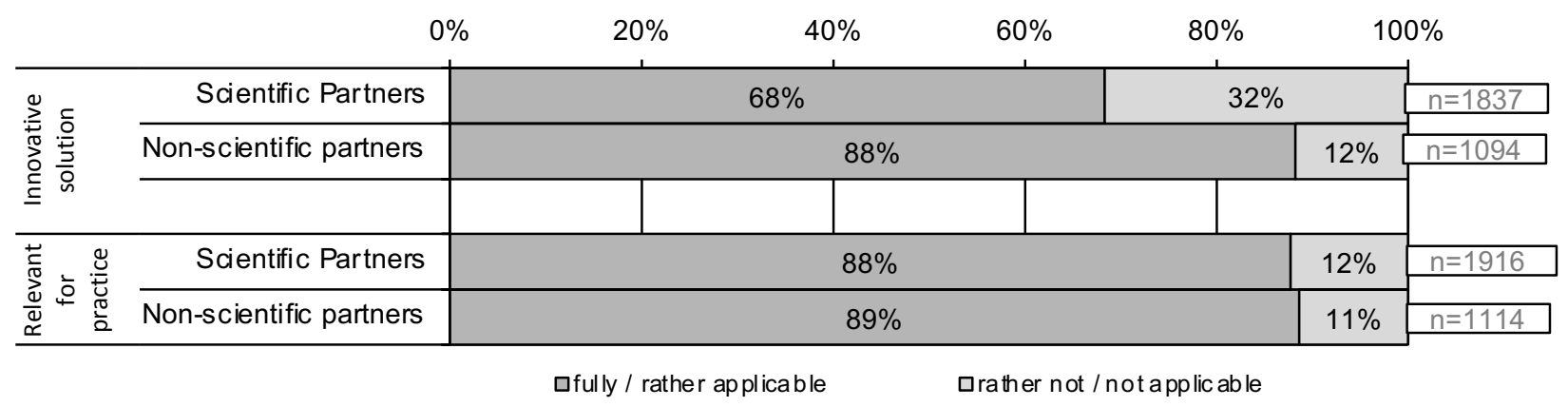

Source: Survey of project leaders 2018, calculation Fraunhofer ISI

Transdisciplinary research projects can provide the initial spark for changes in economic and public organisations. However, such projects are embedded in contexts that heavily influence the conditions for successful transfer and sustainable use of the research results. Figure 6 shows the importance of the framework conditions for transfer success. While a transdisciplinary research project cannot influence the legal conditions, political priorities or organisational structure, it can influence the views and acceptance of the involved project partners on issues related to sustainable development.

Figure 9: Relevance of context for the effectiveness of the funding

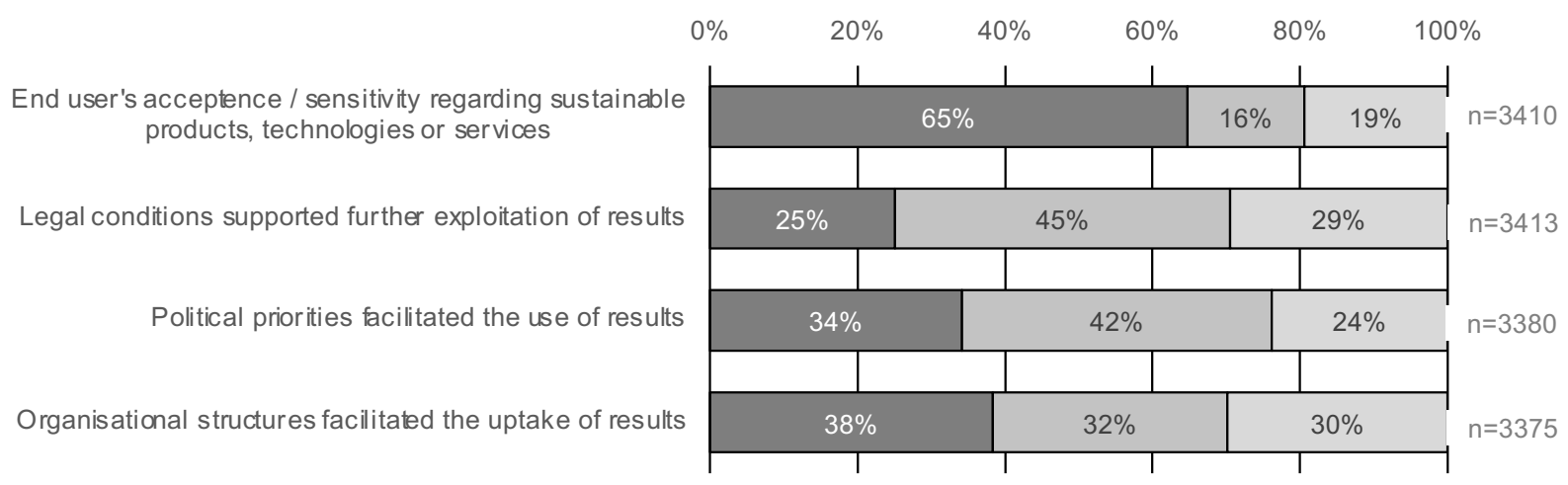

aapplicable $\quad$ arather not / not applicable $\quad$ not relevant 


\section{CONCLUSIONS}

FONA achieves results on different levels, reaches out to different societal domains and thus has effects beyond those of conventional funding schemes. This is a result of the strategic framework with its overarching aims to produce scientific knowledge that is relevant and usable for society and its focus on including new elements of sustainable research (inter- and transdisciplinarity, internationality and a systemic perspective in the research projects and processes). At the same time, FONA has provided a considerable amount of funding over a long period. Good use has been made of the different funding instruments, funding purposes, topics and stakeholder constellations and these have been constantly adapted over the funding periods. FONA can thus be seen as a "learning programme".

Some general lessons learned were derived from conducting this evaluation for future evaluations of research programmes aiming at the transformative change of society, including the science system.

First, context sensitivity is crucial (Bührer et al. 2020a): not only the measure itself, but also its context is decisive for its impact and this is especially true for programmes with the very broad target of institutional change and transformation. For FONA, with its main objectives to direct scientific research towards societal needs and provide the knowledge and solutions required for societal problems, this means that the current logic of research-internal rewards and incentive systems works against changes in the current science system. National programmes can (only) provide impulses here. They send an important signal to other research funding organisations.

Second, given the very slow pace of structural change, the most inappropriate assumptions regarding (complex) policy interventions is that their impacts can and should be observable within a short period and that their success is directly measurable. As the changes in target groups between the three funding periods show, restricting a programme's evaluation to a few years after the programme's or project's completion would miss many valuable effects (for the challenges associated with impact assessments, see, e.g. European Court of Auditors 2008, Reale et al. 2015, Feller 2007).

Third, there is increasing consensus within the evaluation community that interventions only 'contribute' to the outcomes and impacts together with other contextual factors influencing the intervention's outcome (Delahais \& Toulemond 2012, Vanessen \& Raimondo 2012 and Mayne 2012).

From a methodological perspective, a pluralism of methods is a quality criterion for evaluations. However, a qualitative approach focusing on explanatory factors rather than indicators is particularly suitable for complex evaluation objects like FONA. In addition, the long-term perspective that the evaluation was able to adopt (2005-2019) made it possible to qualify (and to some extent quantify) effects that only emerge after years.

The design phase of the evaluation benefitted from laying out and describing the different levels at which the intervention is intended to have effects (in our example, the differentiation into micro-meso-macro levels fitted very well) and differentiating the various impact domains. What was lacking, however, was more intensive stakeholder involvement in all the evaluation phases including the design phase, as required by evaluation scholars (Molas-Gallart et al. 2020). This should be taken into account in the future. However, we also acknowledge the limitations of contract research (typically used for ex-post evaluations), both financial and in terms of the available time.

\section{REFERENCES}

Bührer, Susanne; Kalpazidou Schmidt, Evanthia; Palmén, Rachel; Reidl, Sybille (2020a): Evaluating gender equality effects in research and innovation systems. In: Scientomet-rics 125 (2), S. 1459-1475. D0I: 10.1007/s11192-020-03596-1.

Bührer, Susanne; Wallwaey, Elisa; Walz, Rainer (2021, pre-published): Bestandsauf-nahme und Pilotierung von Konzepten und Methoden der Messung gesellschaftlicher Wirkungen. In: Fraunhofer ISI Discussion Papers Innovation Systems and Policy Analy-sis.

Bührer, Susanne; Walz, Rainer; Seus, Sarah; Astor, Michael; Stehnken, Thomas Fabian Malik (Prognos) (2020b): Evaluation der BMBF-Rahmenprogramme Forschung für die Nachhaltigkeit FONA 1 (2005-2009) \& Forschung für Nachhaltige Entwicklungen FONA 2 (20102014).

Delahais \& Toulemonde, (2012): Applying contribution analysis: Lessons from five years of practice. In: Evaluation 18(3) 281-293.

European Court of Auditors. (2008): Special report No 9/2007 concerning 'Evaluating the EU Research and Technological Development (RTD) framework programmes - could the Commission's approach be improved?' together with the Commission's replies. Brussels: Official Journal of the European Union.

Feller, Irwin (2007): Mapping the frontiers of evaluation of public-sector R\&D programs. In: Science and Public Policy, 34(10), December 2007, pages 681-690.

Gallopín, Gilberto C.; Funtowicz, Silvio; 0'Connor, Martin; Ravetz, Jerry (2001): Science for the Twenty-First Century: From Social Contract to the Scientific Core. In: International Social Science Journal 53 (168), S. 219-229. DOI: 10.1111/1468-2451.00311.

Komiyama, Hiroshi; Takeuchi, Kazuhiko (2006): Sustainability science: building a new discipline. In: Sustain Sci 1 (1), S. 1-6. D0I: 10.1007/ s11625-006-0007-4.

Mayne J (2012): Contribution analysis: Coming of age? In: Evaluation 18(3): 270-280.

Molas-Gallart, Jordi; Boni, Alejandra; Schot, Johan; Giachi, Sandro (2020): A Formative Approach to the Evaluation Of Transformative Innovation Policy. In: TIPC Working Paper (01). Online verfügbar unter http:// www.tipconsortium.net/wp-content/uploads/2020/07/Paper-FORETIP-1. pdf, zuletzt geprüft am 23.02.2021.

Pohl, Christian (2011): What is progress in transdisciplinary research? In: Futures 43 (6), S. 618-626. D0I: 10.1016/j.futures.2011.03.001.

Reale, Emaunela, Dragana Avramov, Kubra Canhial, Claire Donovan, Ramon Flecha, Poul Holm6, Charles Larkin, Benedetto Lepori, Judith Mosoni-Fried, Esther Oliver, Emilia Primeri, Lidia Puigvert4, Andrea Scharnhorst, Andras Schubert, Marta Soler, Sandor Soos, Teresa 
Sorde, Charles Travis and Rene' Van Horik (2015): A review of literature on evaluating the scientific, social and political impact of social sciences and humanities research. Research Evaluation, 27(4), 2018, 298-308.

van den Besselaar, Peter; Heimeriks, Gaston (2001): Disciplinary, Multidisciplinary, In-terdisciplinary -Concepts and Indicators. In: 8th Conference on Scientometrics and In-formetrics, Sydney, Australia.

Vanessen, Jos; Raimondo, Estelle (2012): Making sense of impact: A methodological framework for assessing the impact of prizes In: Evaluation 18 (3), 330-347

Wiek A., Lang D.J. (2016): Transformational Sustainability Research Methodology. In: Heinrichs H., Martens P., Michelsen G., Wiek A. (eds) Sustainability Science. Springer, Dordrecht.

\section{AUTHORS}

\section{SARAH SEUS}

Fraunhofer Institute for Systems and Innovation Research (Germany)

Breslauer Str. 48

76139 Karlsruhe

T: 0049-721-6809-344

E: sarah.seus@isi.fraunhofer.de

ORCID: 0000-0003-0791-5919

\section{SUSANNE BUEHRER}

Fraunhofer Institute for Systems and Innovation Research (Germany)

Breslauer Str. 48

76139 Karlsruhe

T: 0049-721-6809-148

E: susanne.buehrer@isi.fraunhofer.de

ORCID: 0000-0002-1923-1437

KEYWORDS: Evaluation, Sustainability, Sustainability research, Interdisciplinarity, Transdisciplinarity, Transformation (Evaluation, Nachhaltigkeitswissenschaft, Nachhaltigkeit, Interdisziplinarität, Transdisziplinarität, Transformation) 